\title{
PERCEPÇÃO DE IMIGRANTES AFRICANOS SOBRE O ATENDIMENTO NOS SERVIÇOS DE SAÚDE DE PORTUGAL
}

\author{
PERCEPTION OF AFRICAN IMMIGRANTS ABOUT CARE \\ IN HEALTH SERVICES IN PORTUGAL
}

\section{PERCEPCIÓN DE LOS INMIGRANTES AFRICANOS SOBRE LA ATENCIÓN EN LOS SERVICIOS DE SALUD DE PORTUGAL}

\author{
Saionara Costa do Sacramento ${ }^{1}$ \\ Marília Araújo Ferrão ${ }^{2}$ \\ Climene Laura de Camargo ${ }^{3}$ \\ Maria Natália Pereira Ramos ${ }^{4}$ \\ Maria Cecilia Leite de Moraes ${ }^{5}$ \\ Lucas Amaral Martins ${ }^{6}$
}

Como citar este Artigo: Sacramento SC, Ferrão MA, Camargo CL, Ramos MNP, Moraes MCL, Martins LA. Percepção de imigrantes africanos sobre o atendimento nos serviços de saúde de Portugal. Rev baiana enferm. 2020;34:e35989.

Objetivo: conhecer a percepção do imigrante africano sobre o atendimento nos serviços de saúde de Portugal. Método: estudo descritivo com abordagem qualitativa, realizado na Grande Lisboa, Portugal, no período de março de 2017 a janeiro de 2018. Para coleta dos dados utilizou-se a entrevista semiestruturada com imigrantes africanos. A estratificação das informações foi guiada pela análise de conteúdo. Resultados: constatou-se que os serviços de saúde mais utilizados foram os Centros de Saúde e Hospitais; a assistência recebida é de boa qualidade, apesar da dificuldade de acesso, causada pelo longo tempo de espera. Evidenciou-se que as diferenças culturais interferem na compreensão das orientações prestadas e recebidas. Conclusão: o imigrante africano percebe o atendimento que recebe nos serviços de saúde de Portugal como de boa qualidade, ainda que o acesso e a acessibilidade apresente dificuldades decorrentes principalmente das barreiras do preconceito e do racismo.

Descritores: Sistema de Saúde. Acesso aos Serviços de Saúde. Imigração. Países Receptores de Imigrantes. Grupo com Ancestrais do Continente Africano.

Objective: to know the perception of African immigrants about care in health services in Portugal. Method: descriptive study with qualitative approach, conducted in Greater Lisbon, Portugal, from March 2017 to January 2018. For data collection, the semi-structured interview with African immigrants was used. The stratification of the information was guided by content analysis. Results: the health services most used were the Health Centers and Hospitals; the assistance received is of good quality, despite the difficult access, caused by the long waiting time. Cultural differences interfere in the understanding of the orientations provided and received. Conclusion: the African immigrant perceives the

\footnotetext{
Enfermeira. Residente no Hospital Sofia Feldman. Belo Horizonte, Minas Gerais, Brasil. saionaracosta2008@hotmail.com. http://orcid.org/0000-000 I-546I-7426. Enfermeira. Residente em obstetrícia na Secretaria de Saúde do Estado da Bahia. Salvador, Bahia, Brasil. http://orcid.org/0000-0002-9379-94 I8.

Enfermeira. Doutora em Saúde Pública. Docente da Universidade Federal da Bahia. Salvador, Bahia, Brasil. http://orcid.org/0000-0002-4880-39I6

Psicóloga. Doutora em Psicologia Clínica Intercultural. Professora Associada da Universidade Aberta de Lisboa. Lisboa, Portugal. http://orcid.org/0000-00028448-1846.

5 Terapeuta Ocupacional. Doutora em Saúde Pública. São Paulo, São Paulo, Brasil. http://orcid.org/0000-0002-87| 7-65। 3.

6 Enfermeiro. Mestre em Enfermagem. Docente da Universidade Federal do Recôncavo da Bahia. Cachoeira, Bahia, Brasil. http://orcid.org/0000-0003-I497-6576.
} 
care received in health services in Portugal as of good quality, even though access and accessibility present difficulties resulting mainly from the barriers of prejudice and racism.

Descriptors: Health System. Access to Health Services. Immigration. Immigrant Receiving Countries. African Continental Ancestry Group.

Objetivo: conocer la percepción de los inmigrantes africanos sobre la atención en los servicios de salud en Portugal. Método: estudio descriptivo con enfoque cualitativo, realizado en la Gran Lisboa, Portugal, de marzo de 2017 a enero de 2018. Para la recopilación de datos, se utilizó la entrevista semiestructurada con inmigrantes africanos. La estratificación de la información se guio por el análisis de contenido. Resultados: se encontró que los servicios de salud más utilizados eran los Centros de Salud y Hospitales; la asistencia recibida es de buena calidad, a pesar de la dificultad de acceso, causada por el largo tiempo de espera. Se evidenció que las diferencias culturales interfieren en la comprensión de las orientaciones proporcionadas y recibidas. Conclusión: el inmigrante africano percibe la atención que recibe en los servicios de salud en Portugal como de buena calidad, a pesar de que el acceso y la accesibilidad presentan dificultades resultantes principalmente de las barreras de los prejuicios y el racismo.

Descriptores: Sistema de salud. Acceso a los Servicios de Salud. Inmigración. Países Receptores de Inmigrantes. Grupo de Ascendencia Continental Africana.

\section{Introdução}

O fortalecimento da multi/interculturalidade nas sociedades e da coabitação com a diversidade, são fatores decorrentes da globalização e do aumento das migrações no mundo, o que exige a adoção de novas práticas, estratégias e políticas adequadas às necessidades educacionais, comunicacionais e sanitárias da coletividade ${ }^{(1)}$.

Os processos migratórios trazem aspectos positivos e negativos que variam segundo a ótica circunstancial. A diminuição da distância intercultural entre nações é um dos pontos fortes do processo, considerando que é um fator de aproximação e integração dos diferentes povos. Por outro lado, essa aproximação envolve a complexidade que se estabelece nas interrelações entre imigrantes e cidadãos nativos, as quais podem ser conflituosas, principalmente no que tange ao acolhimento e à divisão de bens e recursos públicos, como, por exemplo, os serviços de saúde ${ }^{(2)}$.

As relações entre os processos migratórios e a saúde são atravessadas pela complexidade e multifatorialidade, o que coloca em discussão implicações econômicas, culturais e históricas em que se encontram. Diferentes questões de saúde concorrem nessas circunstâncias e exigem respostas eficientes por parte de profissionais e gestores dos sistemas oficiais de saúde ${ }^{(3)}$.

Cabe salientar que as questões de saúde dos imigrantes estão no centro das preocupações internacionais, já que são fundamentais para sua integração no país de acolhimento, independentemente de sua condição social, econômica ou cultural. A assistência à saúde deve estar estruturada para atender as demandas dos cidadãos estrangeiros, considerando que estão expostos a situações de vulnerabilidade, por experimentarem mudanças e uma nova cultura, geralmente diversa de seu país de origem ${ }^{(4)}$.

A temática "saúde dos imigrantes" inclui um leque de conjunturas, dentre as quais ressaltam-se: as ações de promoção da saúde e prevenção da doença; o acesso aos serviços e cuidados de saúde; o tratamento e a reabilitação; além da acessibilidade linguística, cultural e material $^{(5)}$.

Em vários países do mundo, principalmente na União Europeia, os imigrantes são identificados como uma população em risco de pobreza e exclusão social, o que tem servido de alerta para o desenvolvimento de medidas igualitárias ${ }^{(5)}$. Entretanto, são os imigrantes de países africanos, os que mais sofrem, pois, além dos problemas advindos das questões econômicas e socioculturais, enfrentam também a discriminação racial, apesar da legislação de alguns países, como Portugal, por exemplo, prever medidas de atenção ao imigrante independentemente da sua origem, nacionalidade e condição legal no território.

Apesar de as estatísticas de imigração relativas a estrangeiros residentes em Portugal não darem conta da enorme parcela daqueles que possuem 
nacionalidade portuguesa, é possível afirmar que a população de origem africana e afrodescendente em Portugal é numerosa, apesar de todos os entraves sociais e econômicos que vivenciam, agravados pelo racismo.

Os imigrantes cabo-verdianos ocupam o segundo lugar no ranking imigratório em Portugal, o que representa 34.986 habitantes, isto é, 8,3\% da população estrangeira; os brasileiros lideram com 20,3\% do contingente, o que compreende 85.426 habitantes ${ }^{(6-7)}$.

No plano normativo, o Serviço Nacional de Saúde português é definido (art. 64) como universal, geral e tendencialmente gratuito. Além de subdividido em instâncias de complexidade, tem como base a promoção e a proteção da saúde e recuperação de danos. Com isso, a Constituição da República Portuguesa chancela o direito à saúde para todos os cidadãos (art. 64). O acesso igualitário de imigrantes e da população portuguesa aos serviços, tratamentos e medicamentos está garantido pelo Decreto Lei no 135/99, do Ministério da Saúde ${ }^{(8)}$, que faculta o acesso ao Serviço Nacional de Saúde aos imigrantes que não sejam titulares de uma autorização de residência ou encontrem-se em situação irregular face à legislação imigratória em vigor.

Apesar de o acesso à saúde ser direito essencial à vida, são identificadas certas dificuldades no acesso e na assistência prestados pelos serviços de saúde português, que são corriqueiramente enfrentados pelas populações nacionais e de imigrantes. Essas dificuldades abarca aspectos organizacionais, interpessoais, bem como a falta de informação, tanto da parte desses grupos como dos próprios profissionais de saúde e instituições de saúde em relação à legislação, aos direitos e aos deveres desses nos serviços de saúde $^{(4)}$. Concomitantemente, embora a regulamentação do Sistema Nacional de Saúde (SNS) assegure o acesso e direitos dos imigrantes à saúde, na prática há dificuldades em atender as demandas dessa população, de modo a garantir a qualidade e a equidade em saúde ${ }^{(5)}$.

Assim, esta pesquisa busca revelar como é o atendimento nos serviços de saúde em Portugal para os imigrantes africanos, revelando, assim, as fragilidades e potencialidades desses serviços e, quiçá, subsidiar políticas públicas de atenção à saúde de imigrantes. Nessa perspectiva, objetiva conhecer a percepção do imigrante africano sobre o atendimento nos serviços de saúde de Portugal.

\section{Método}

Trata-se de um estudo descritivo, exploratório, com abordagem qualitativa. Realizado no período de março de 2017 a janeiro de 2018 na Grande Lisboa, Portugal, nos municípios de Sintra e Amadora, os quais concentram imigrantes oriundos dos países africanos de Língua Oficial Portuguesa e integraram o local do intercâmbio estudantil Abdias Nascimento ${ }^{(9)}$.

A aproximação com a temática e com os participantes deu-se por meio dos projetos intitulados "Rede Internacional de Pesquisa: Saúde, Ambiente e Desenvolvimento Social" e "Imigrantes Negras: uma População a ser Descoberta”, desenvolvidos pela Escola de Enfermagem da Universidade Federal da Bahia, localizada no Brasil, em parceria com o Centro de Estudos das Migrações e das Relações Interculturais (CEMRI) da Universidade Aberta de Lisboa (Uab), em Portugal, por meio do Programa de Mobilidade e Desenvolvimento Acadêmico Abdias Nascimento, o qual possibilitou o intercâmbio de pesquisadores para a realização de parceria interinstitucional e desta pesquisa.

A aproximação com os participantes deu-se em parques públicos e estações de comboio (meio de transporte ferroviário de Portugal), pontos de encontro frequentados diariamente pelos imigrantes, localizados em bairros predominantemente habitados pelos imigrantes africanos. Nesses espaços, os pesquisadores contactavam o participante, apresentavam a pesquisa e convidava-o para participar. Assim, foram selecionados oito imigrantes africanos (sete mulheres e um homem) que atenderam aos critérios de elegibilidade: residir em Portugal por um período mínimo de 1 ano e ser africano. O critério de exclusão foi não ter buscado/utilizado serviços de saúde de Portugal. 
A coleta de dados foi realizada por meio da entrevista semiestruturada e diário de campo. As entrevistas foram gravadas e realizadas em um banco do parque ou da estação de comboio, de forma isolada, para garantir o sigilo das informações, com duração média de 20 minutos. As entrevistas foram guiadas pela seguinte questão: "Qual a sua percepção sobre o atendimento dos serviços de saúde de Portugal?" Dados adicionais, como cultura/etnia, sexo, escolaridade, estado civil, atividade profissional, foram solicitados aos participantes para aproximação e estabelecer o perfil sociodemográfico. Após o término, cada entrevista foi escutada pelo pesquisador e participante, para obter a aprovação das informações disponibilizadas. Após a aprovação, procedeu-se à transcrição.

A análise dos dados foi guiada pelo modelo de análise de conteúdo proposta por Bardin ${ }^{(10)}$. Inicialmente foi realizada a leitura flutuante, seguida de leitura minuciosa das entrevistas, para possibilitar o agrupamento das falas por aproximação temática. Esta sequência possibilitou a organização do conteúdo em quatro categorias temáticas.

Ressalta-se que os aspectos éticos estabelecidos para as pesquisas que envolvem seres humanos foram respeitados, conforme normas nacionais e internacionais regulamentadoras das pesquisas. O projeto foi submetido e aprovado pelo Comitê de Ética em Pesquisa da Universidade Federal da Bahia. Elaborou-se o Termo de Consentimento Livre e Esclarecido (TCLE), que foi lido e assinado pelos participantes. Para assegurar o anonimato deles, os nomes foram substituídos pela letra "I" (Imigrante), seguida de número cardinal crescente, conforme a ordem da entrevista (I1 até I8).

\section{Resultados e Discussão}

Identificou-se que os participantes eram oriundos da Angola, Cabo Verde, Guiné Bissau e São Tomé e Príncipe, Países Africanos de Língua Oficial Portuguesa (PALOP); a idade variou de 19 a 45 anos. Em relação ao estado civil, 50\% eram solteiros, 37,5\% viviam em união estável e 12,5\% eram casados. Quanto ao número de filhos, variou de 1 a 3; referente à escolaridade, $37,5 \%$ possuiam nível primário concluído e 62,5\% concluíram o ensino médio. Quanto ao tempo de residência em Portugal, foi identificada uma variação de 1 a 20 anos.

Após a análise das entrevistas foi possível agrupar as informações nas seguintes categorias: "Serviços de Saúde mais utilizados", "Percepção sobre o atendimento nos serviços de Saúde de Portugal", "Diferenças culturais no cuidado" e "Sugestões para melhoria do acesso e da qualidade dos cuidados de saúde".

\section{Serviços de Saúde mais utilizados}

Os imigrantes africanos que residiam em Portugal relataram que os serviços de saúde mais utilizados eram os Centros de Saúde e os Hospitais.

Eu vou mais aos hospitais por causa das urgências e para fazer algum exame específico. (I1).

Procuro mais o Centro de Saúde e o Hospital. (I2).

Salienta-se que, durante a pesquisa, foi constatado que os imigrantes que já passaram pelo processo de integração tendiam a usufruir mais dos serviços de saúde e a participarem das atividades sociais, quando comparados ao imigrante recém-chegado no país, já que os imigrantes ilegais ficavam com medo de se expor, para não serem descobertos.

Desde 2001, as leis portuguesas reconhecem aos imigrantes o direito de acesso aos cuidados de saúde dos centros de saúde e hospitais do Serviço Nacional de Saúde (SNS) ${ }^{(11)}$. Entretanto, na prática, esse direito nem sempre é respeitado, pois existem imigrantes em situação ilegal, que nem sempre são aceitos nos serviços de saúde (em especial, os serviços que não são de emergência), justamente pelo fato de não possuírem os documentos exigidos no ato do atendimento à saúde, tais como: comprovante de residência e número de identificação fiscal (NIF).

Acordos de Cooperação Internacional no Domínio da Saúde visam assegurar, nas mesmas condições dos cidadãos nacionais, a assistência médica de pessoas com problemas 
de saúde, evacuados dos PALOP, que se deslocam para Portugal, com o propósito de lhes serem prestados cuidados hospitalares ou em regime ambulatorial, para os quais o sistema de saúde do país de origem não tem capacidade técnica para prestar. Neste sentido, essas pessoas estão sujeitas às regras de procedimento de acesso ao Serviço Nacional de Saúde (SNS), que os distinguem dos demais cidadãos estrangeiros que recorrem ao SNS, por força da aplicação dos referidos acordos de cooperação ${ }^{(11)}$. O acesso e a continuidade dos cuidados de saúde dos imigrantes em Portugal mais frequentes dizem respeito a: desconhecimento dos seus direitos e dos locais para onde se devem deslocar para acessá-los; dificuldades administrativas; custos dos tratamentos; isolamento familiar; discriminação, exclusão e falta de suporte social; medo de serem denunciados, em caso de clandestinidade; precariedade das condições econômicas, habitacionais e laborais; hábitos e crenças culturais; e barreiras culturais, linguísticas e comunicacionais ${ }^{(1)}$.

\section{Percepção sobre o atendimento nos serviços de Saúde de Portugal}

$\mathrm{Na}$ percepção dos imigrantes africanos que buscaram atendimento nos serviços de saúde de Portugal, foram bem atendidos, tiveram assistência de qualidade, com profissionais atenciosos e cuidadosos. Os relatos são ilustrativos:

[...] não tenho razão de queixa nenbuma, porque o meu filho, há pouco tempo teve um pequeno problema [...] e foi bastante bem-atendido. (I1).

O serviço de saúde daqui é muito bom. O atendimento também, e os médicos, acredito que eles estão ali a fazer o que gostam. (I7).

[...] dão livros e as enfermeiras fazem questão de explicar tudo, mesmo na gravidez, desde o inicio da gravidez, o que podes comer, o que deve ter atenção, as consultas e essas coisas [...] as enfermeiras estão sempre em cima $e$, mesmo quando nasce, acompanham pra saber como está a pele, as manchas, a higiene do bebê [...] aí ficam mais em cima, porque é a profissão delas e depois dizer à médica, e a médica escuta e fica tudo anotadinbo. (I8).

Na avaliação da satisfação dos usuários nos serviços de saúde, a atuação dos profissionais de saúde deve ser considerada, uma vez que, além de informarem e prestarem cuidados, devem investir na construção de uma relação empática com os indivíduos. É de vital importância que os profissionais elaborem profícuos canais de comunicação, para informar de modo claro e humano sobre a situação de saúde dos imigrantes, considerando as adversidades já experimentadas por esses sujeitos. Esta circunstância constitui um grande desafio e pode ser um dos fatores a interferir ou não no uso dos serviços de saúde por essa população ${ }^{(12)}$.

Os imigrantes verbalizaram a insatisfação com o tempo de atendimento e as filas enfrentadas no serviço de saúde de Portugal.

[...] costuma ter muito tempo de espera [...] (I1).

O acesso, as filas nos hospitais, que demoram muito a serem atendidos. (I6).

O chato daqui é a demora sabe? E os médicos aqui são poucos. $E$ chato porque os enfermeiros ficam decepcionados com a carga de trabalho, com o ordenado e então desgasta. (I7)

Tens que esperar muito. (I8)

O tempo de espera para atendimento nos serviços de saúde em Portugal pode ser reflexo de uma procura mais intensa da população, em especial aos serviços de urgência e emergência, que vem crescendo acentuadamente. O elevado tempo de espera constitui-se em um problema comum em sistemas públicos de saúde e reflete negativamente na qualidade da asssitência ${ }^{(12)}$. Apesar de os serviços de saúde europeus serem reconhecidos por sua eficiência quando comparados a outros países, os longos períodos de espera têm-se tornado um problema crônico, que poderão interferir na avaliação pública desse quesito ${ }^{(13)}$.

Conforme exposto na fala de 17 , pode-se inferir que um dos fatores que causa a demora no atendimento nos serviços hospitalares é o número reduzido de profissionais. Este fator gera sobrecarga de trabalho para os profissionais e insatisfação do paciente. Salienta-se que as cargas de trabalho causam prejuízos à saúde dos trabalhadores, à instituição e à assistência segura ao paciente ${ }^{(14)}$. 
Os imigrantes também evidenciaram a qualidade da estrutura do hospitais de Portugal e sinalizaram a falta de valorização das queixas dos pacientes, a exemplo da dor, que pode ser sintoma de uma doença mais grave.

Em termos de saúde em Portugal, temos hospitais muito bem preparados, mas, em casos de algumas doenças, não. Confesso que Portugal não está bem preparado para algumas situações [...] às vezes até não dão importância a uma simples dor que tu tenhas e pode ser bastante grave. Portanto, acho que os serviços aqui não estão bem-preparados para algumas situações [...] (I1).

A respeito da fala do I1, como exemplo dessa realidade, pode-se citar a epidemia vivenciada recentemente na África com o ressurgimento do vírus Ebola, no maior surto até então registrado na história atual. Com isso, evidencia-se que, para determinadas epidemias ou determinantes de saúde, existem países e continentes que realmente precisam ser melhor preparados. Isso se torna uma preocupação ainda maior, quando as comunidades científicas e o governo não dão a devida atenção para essa questão. Esse fato, que pode estar associado à alta receptividade de imigrantes no país, além de outros fatores, como o envelhecimento progressivo da população, acaba por elevar o índice de doenças crônicas e a procura por atendimento ${ }^{(6)}$.

\section{Diferenças culturais no cuidado}

Esta categoria refere-se às diferenças identificadas pelos imigrantes, na comparação dos cuidados prestados em Portugal e em países africanos.

Aqui se trata mais com remédio do que em Angola. Por exemplo, aqui se usa o Bebegel [laxante para bebês e crianças] e em Angola se usa um cotonete com azeite. (I3).

Aqui ensina que, quando o bebê nasce, sempre tem que ter muito cuidado, a maneira da gente pegar o recém-nascido, a maneira também de dar o banbo. Geralmente, em Angola, nós usamos o azeite de Palma. Aí nossas mamães aquecia ou então queima-se as teiras, e então tratavam-se o umbigo e aquilo ia pondo no umbigo da criança e vai secando até cair. (I4).

Quando uma criança tem papeira [Caxumba] põe cinzas, usa o carvão depois da gente grelhar. Então, utiliza-se aquela cinza e o vinagre põe-se. Uma das vezes aconteceu comigo, eu levei meu filho lá em Angola, aí eu falei vou levar no médico, e uma senhora me disse: "não é preciso. Aqui não tratamos a papeira assim. É só pegares a cinza, aquela cinza assim do carvão depois de grelhar, põe o vinagre e vais pondo na criança”. E olba, né que resultou? Resultou. E passou. (I4).

Estudo traz que a população cabo-verdiana utiliza remédios da terra e estes envolvem tudo o que tenha a ver com a prevenção e o diagnóstico da doença. Em Cabo Verde, o remédio e os tratamentos naturalistas, também chamados remédios da terra, e a medicina convencional coexistem no mesmo espaço social, com plena aceitação por parte da população, apesar da necessária adaptação de novas técnicas e novos valores que são introduzidos pelo progresso médico da medicina dita "moderna"

Quando os imigrantes de origem africana chegam no país de acolhimento, é comum deixarem as práticas de cuidado naturalista utilizadas em seus países de origem, já que não são reconhecidas e valorizadas nos países ditos desenvolvidos. Neste sentido, desenvolvem várias adaptações ao seu estilo de vida e tornam-se participantes da nova cultura, muitas vezes em detrimento de seus valores nativos. Isto é, passam pela "aculturação", conceito que designa um processo dinâmico de mudança social e cultural que acontece pelo contato, direto ou indireto, entre grupos sociais distintos.

Outro ponto a ser discutido é sobre as diferenças no que diz respeito à alimentação infantil, evidenciado na seguinte fala:

Lá em Angola é diferente daqui. Lá se dá mingau de milho e aqui diz que é só o leite materno. (I3).

Para promover melhor cuidado nos diferentes contextos culturais, é importante considerar as diversas formas de pensar, os saberes e as práticas de saúde e entender a influência de cada cultura na existência do cuidado, porém sem perder a essência da proteção e do afeto nas ações desse cuidado ${ }^{(16)}$.

Estudo $^{(17)}$ ressalta que os descendentes de africanos têm a cultura de introduzir precocemente os engrossantes na alimentação das crianças concomitante ao leite materno. Revela ainda que o aleitamento materno é um ato universal, porém sua prática é diversificada e sofre influência de diversas culturas. Por isso, cabe aos profissionais de saúde orientarem as práticas de 
cuidado conforme os valores culturais de cada população.

Em se tratando do cuidado à criança, essa influência cultural torna-se ainda mais evidente. Portanto, é imprescindível conhecer o contexto sociocultural das mães, bem como identificar seus saberes e práticas de cuidado, para compreender suas crenças, valores e costumes na prática de atenção com a saúde ${ }^{(18-19)}$.

O relato de $\mathrm{I} 3$ permite identificar-se que, para situações semelhantes, existem formas diferentes de cuidar, corroborando estudo ${ }^{(19)}$ que identifica a importante influência da cultura nos cuidados prestados às crianças, seja na higiene, nos hábitos alimentares, no desmame e no uso de plantas medicinais. Estes são exemplos de práticas influenciadas por representações e valores culturais transmitidos entre gerações, que norteiam o cotidiano de cuidados dispensados às crianças ${ }^{(19)}$.

Apesar de muitas vezes abandonarem os tratamentos naturais utilizados em seus países de origem, algumas práticas relacionadas às suas crenças, valores e mitos são preservados, mantendo-se ativas por gerações. Como exemplo deste fato, salienta-se a circuncisão, como pode ser percebido na seguinte fala:

[...] lá, quando as crianças nascem, são circuncisados e aqui não. E, por exemplo, lá, quando a criança nasce, é circuncisado né, mas, ao circuncisar, não passa por exames, nem análises, nem nada, mas aqui, para uma criança ser circuncisada, primeiro tem que fazer os exames, análises, os médicos mandam fazer " $n$ " exames e só assim que a criança é circuncisada. (I4).

A circuncisão está, sobretudo, ligada a fatores culturais e religiosos. Para alguns povos, é uma forma de simbolizar o pertencimento de um indivíduo a um determinado grupo social. É realizada como modo ritualístico para os judeus, alguns grupos muçulmanos e povos rurais de alguns países africanos, como, por exemplo, no Quênia e na África do Sul. Nestes países, a circuncisão é feita em adolescentes, nas escolas de iniciação, e é realizada por leigos, com incidência significativa de complicações clínicas. Este fato levou o governo da África do Sul a desenvolver políticas de redução de danos à saúde, em detrimento da erradicação da prática da circuncisão, como, por exemplo, o treinamento de técnicas assépticas, entre outras ${ }^{(20)}$.

Nesse contexto, pode-se perceber nessa fala que, apesar do ato da circuncisão ser realizado tanto nos países africanos de origem como em Portugal, a maneira de fazê-lo, no país lusófono, foi considerada diferente, possibilitando menos riscos para a saúde da criança.

\section{Sugestões para melhoria do acesso e qualidade dos cuidados de saúde}

Durante as entrevistas, os participantes apontaram várias situações que impactavam na atenção recebida e deviam ser melhoradas, a exemplo do que se segue na próxima fala:

[...] eu acho que os médicos deveriam fazer mais, dar
mais atenção aos doentes. Tem muita falta de atenção.
Eu não sei se eles estão aborrecidos com carga de traba-
lho, não estão satisfeitos e por isso estão sempre em greve,
e aí vais ao centro de saúde e não há médicos. É mesmo
o atendimento que falta é muito demorado. Tu vais desde
manhã e só sai de lá à noite. É chato. (I7).

A crise financeira internacional acentuou as pressões econômicas sobre os sistemas nacionais de saúde, acarretando redução de gastos, sobretudo por meio de cortes de pessoal e em assistência farmacêutica. Como consequência imediata, houve aumento significativo do tempo de espera dos usuários dos serviços de saúde, afetando a todos os indivíduos, independentemente de serem nacionais ou imigrantes ${ }^{(21)}$.

Outra consideração importante feita pelos imigrantes foi a respeito da comunicação com profissionais de saúde:

\section{Ser mais ouvido pelos profissionais de saúde, quando for na consulta, para não ter que ficar voltando 3, 4 vezes com o mesmo problema. (I3).}

A comunicação deve melhorar. (I6).

Este achado corrobora o entendimento de outros pesquisadores $^{(22)}$, ao afirmarem que, no âmbito da saúde, é necessário valorizar a compreensão dos contextos de vida e o significado do adoecimento, mostrar-se aberto a acolher o sofrimento do outro e desenvolver habilidades comunicacionais, além de considerar que, nesse Sistema, é comum evidenciar barreiras étnico/ culturais, como a falta de sensibilidade cultural 
por parte dos profissionais de saúde e a falta de uma escuta qualificada. Enquanto as primeiras ocorrem na entrada do sistema, as segundas acontecem num momento mais avançado com o provedor do serviço ${ }^{(22)}$.

A escuta qualificada, o diálogo e a atenção às manifestações não verbais devem ser colocados em prática em todo tipo de atendimento, independentemente do público. Entretanto, é no atendimento à população africana que é necessária maior atenção, com vistas a dirimir os resquícios do preconceito e do racismo, enquanto fatores impeditivos de um acolhimento profícuo.

Outra observação feita pelos participantes foi sobre a disponibilidade de mais instituições e profissionais de saúde em Portugal:

Ter mais centros de saúde, profissionais [...] ter mais médicos para as famílias serem acompanhadas. (I4).

Segundo a Lei de bases do Serviço Nacional de Saúde sobre o Estatuto dos Usuários (art. 23), é direito dos usuários dos serviços de saúde de Portugal apresentar, individual ou coletivamente, petições, sugestões, reclamações ou queixas sobre a organização e o funcionamento do Serviço Nacional de Saúde ${ }^{(23)}$.

Dados do State of Health in the UE sobre o perfil de saúde de Portugal em 2017 informam que esse país está entre aqueles da União Europeia (UE) que estão em condição superior à média da UE quanto ao quantitativo de médicos contratados, o que ainda não é suficiente para o atendimento integral da população residente em Portugal. Como agravante, ainda tem o número de enfermeiros, que é inferior ao ideal, apesar do crescimento verificado durante a última década, sendo 6,3 por 1.000 habitantes, enquanto o ideal seria de 8,4 por $1.000^{(24)}$.

Destaca-se como limitação do estudo a dificuldade de acesso e captação de participação para a pesquisa, pois os imigrantes em situação ilegal no país apresentavam resistência em fornecer quaisquer informações e estabelecer contato, devido ao medo de serem descobertos.

\section{Conclusão}

Este estudo permitiu descrever aspectos importantes dos serviços de saúde de Portugal e as percepções de imigrantes africanos sobre a assistência recebida. Para os participantes deste estudo, os serviços de saúde mais utilizados foram os Centros de Saúde e os Hospitais. Mencionou-se, de maneira significativa, que a assistência recebida era de boa qualidade, apesar da dificuldade de acesso, causada pelo longo tempo de espera. As diferenças culturais interferiam na compreensão das orientações prestadas e recebidas.

No que diz respeito ao profissional de saúde, percebeu-se a necessidade de implementação de ações educativas, para que fosse adotada a perspectiva intercultural nos processos de diálogo e comunicação, contribuindo, assim, para uma realidade consciente da pluralidade social e cultural. Desse modo, é possível promover a integração e o respeito à diversidade, a superação de preconceitos culturais e do etnocentrismo.

Diante do exposto, percebeu-se que, apesar da mudança de país levar a uma ruptura das relações sociais, desconhecimento da nova realidade social e cultural, o modo de funcionamento das instituições do país de acolhimento, sobretudo dos serviços de saúde e a falta de relações de confiança, os imigrantes que participaram desta pesquisa, apesar de terem conhecimento de seus direitos enquanto cidadãos, muitas vezes não conseguiam vencer as barreiras do preconceito e do racismo, para garantirem o acesso e a acessibilidade aos Sistema de Saúde. Há especificidades próprias a esses grupos que provavelmente são desconhecidas dos profissionais de saúde nos diversos níveis de atenção, como também há desconhecimento dos imigrantes sobre a forma como esse cuidado é realizado.

Existe uma preocupação acentuada do governo português em desenvolver políticas públicas e prestar assistência de saúde aos imigrantes, já que estes representam uma parcela cada vez maior da população residente no país. Desta forma, é necessário que profissionais de saúde, gestores e políticos busquem apreender o cuidado transcultural, entendido como a essência da área de saúde, designadamente da enfermagem, seja planejando, seja implementando ações com o intuito de melhorar as condições de vida e promover a saúde e o bem-estar de 
indivíduos, grupos e comunidades nacionais ou imigrantes.

\section{Colaborações:}

1 - concepção, projeto, análise e interpretação dos dados: Saionara Costa do Sacramento, Marília Araújo Ferrão, Climene Laura de Camargo e Maria Natália Pereira Ramos;

2 - redação do artigo e revisão crítica relevante do conteúdo intelectual: Saionara Costa do Sacramento, Marília Araújo Ferrão, Climene Laura de Camargo, Maria Natália Pereira Ramos, Maria Cecilia Leite de Moraes e Lucas Amaral Martins

3 - aprovação final da versão a ser publicada: Climene Laura de Camargo.

\section{Referências}

1. Franken I, Coutinho MPL, Ramos MNP. Representações sociais, saúde mental e imigração internacional. Psicol ciênc prof. 2012;32(1):202-19. DOI: http://dx.doi.org/10.1590/S1414-9893201200 010001

2. Neto F. Psicologia Social Aplicada. Lisboa: Universidade Aberta; 2004.

3. Granada D, Carreno I, Ramos N, Ramos MCP. Discutir saúde e imigração no contexto atual de intensa mobilidade humana. Interface (Botucatu). 2017;21(61):285-96. DOI: 10.1590/ $1807-57622016.0626$

4. Ramos MNP. Comunicação em Saúde e Interculturalidade - Perspectivas Teóricas, Metodológicas e Práticas. RECIIS - Rev Eletr Com Inf Inov Saúde [Internet]. 2012 [cited 2018 Feb 12];6(4):32-41. Available from: https://www. reciis.icict.fiocruz.br/index.php/reciis/article/ view/742/1385

5. Padilha B. Saúde dos imigrantes: multidimensionalidade, desigualdades e acessibilidade em Portugal. REMHU, Rev Interdiscip Mobil Hum [online]. 2013;1(40):49-68. DOI: $\quad$ https://doi.org/10.1590/S1980-85852013 000100004

6. Serviço de Estrangeiro e Fronteiras. Dados estatísticos de Imigrantes residentes em Portugal [Internet]. Portugal; 2014 [cited 2017 Oct 16].
Available from: https://www.om.acm.gov.pt/ dados-estatisticos

7. Oliveira C, Gomes N. Indicadores de integração de imigrantes: relatório estatístico anual 2018 [Internet]. Lisboa: Observatório das Migrações; 2018 dez. Coleção Imigração em Números [cited 2018 Feb 13]. Available from: https://www. om.acm.gov.pt/documents/58428/383402/Re lat $\%$ C 3\%B3rio+Estat $\%$ C 3\%ADstico + Anua $1+2018+\%$ E $2 \% 80 \% 93+$ Indicadores $+d e+I n$ tegra\%C3\% A 7\% C3\% A $30+d$ e + Imigrantes. pdf/00de4541-b1ad-42ed-8ce9-33056321ecdb

8. Portugal. Ministério da Saúde. Decreto-Lei no ${ }^{0}$ 11, de 15 de Janeiro de 1993. Aprova o Estatuto do Serviço Nacional de Saúde 2013 [Internet]. Lisboa; 1993 [cited 2017 Sep 9]. Available from: https://dre. pt/web/guest/pesquisa/-/search/586006/details/ normal?l=1

9. Instituto Nacional de Estatística de Portugal. População proveniente dos países Africanos de Língua Oficial Portuguesa [Internet]. Lisboa; 2012 [cited 2018 Apr 16]. Available from: https://www. ine.pt/xportal/xmain?xpid=INE\&xpgid=ine_inst_ publicacoes\&xlang $=\mathrm{pt}$

10. Mozzato AR, Grybovski D. Análise de conteúdo como técnica de análise de dados qualitativos no campo da administração: potencial e desafio. RAC. 2011 jul-ago [cited 2017 Nov 23];15(4):731-47. Available from: https://www.scielo.br/pdf/rac/ v15n4/a10v15n4.pdf

11. Portugal. Ministério da Saúde. Manual de acolhimento no acesso ao sistema de saúde de cidadãos estrangeiros. Rev Elaborar [Internet]. 2015 [cited 2019 Jun 1];2(1). Available from: https://www. sns.gov.pt/wpcontent/uploads/2017/03/CHLeiria_ CidadaosEstrangeiros_ManualAcolhimento.pdf

12. Silva Junior GB, Dias ER. Avaliação da satisfação dos usuários de um serviço de saúde públicoprivado no Nordeste do Brasil e a judicialização da saúde. R Dir sanit. 2016 jul/out;17(2):13-29 DOI: http://dx.doi.org/10.11606

13. Esperidião MA, Vieira-da-Silva LM. Posição social e julgamento dos serviços de saúde pelos usuários. Saúde Soc. 2016 jun;25(2):381-91. DOI: https://doi.org/10.1590/S0104-12902016148416

14. Carvalho DP, Pereira LR, Geri JTB, Dias JSD, Schallenberger CD. Cargas de trabalho e a saúde do trabalhador de enfermagem: revisão integrativa. Cogitare Enferm. 2017 jan/mar;22(1):1-11. DOI: http://dx.doi.org/10.5380/ce.v22i1.46569 “ 
15. Backstrom B. O acesso à saúde e os factores de vulnerabilidade na população imigrante. Alicerces [Internet]. 2010 [cited 2020 Sep 9];III(3):79-90. Available from: https://core.ac.uk/download/ pdf/61420839.pdf

16. Oliveira EAR, Rocha SS. O Cuidado Cultural dos Pais na Promoção do Desenvolvimento Infantil. Rev Fund Care Online. 2019;11(n.esp):397-403. DOI: $\quad$ http://dx.doi.org/10.9789/2175-5361.2019. v11i2.397-403

17. Martins LA, Oliveira RM, Camargo CL, Aguiar ACSA, Santos DV, Whitaker MCO, et al. Prática do aleitamento materno em comunidades quilombolas à luz da teoria transcultural. Rev Bras Enferm. 2020;73(4):e20190191. DOI: https://doi. org/10.1590/0034-7167-2019-0191

18. Takemoto AY, Zarpelon NF, Rossetto EG. Práticas populares no cuidado infantil: percepção das mães. Rev Rene. 2019;20:e40075. DOI: 10.15253/2175-6783.20192040075

19. Ramos MNP. Mães e famílias entre culturas: saúde, desenvolvimento e cuidados interculturais. In: Rocha MMS, Ramos MNP, Santos SMM, Costa MDH, organizadoras. Seguridade social, Interculturalidades e Desigualdades na Contemporaneidade [Internet]. Rio Grande do Norte: Edufrn; 2016. p. 230-70 [cited 2018 Apr 5]. Available from: file://C:/Users/Netbook/ Documents/Downloads/M\%C3\%A3es\%20e\%20 familias\%20entre\%20culturas_2016.pdf

20. Palhares D, Squinca F. Os desafios éticos da mutilação genital feminina e da circuncisão masculina. Rev bioét [online]. 2013;21(3):432-7.
DOI: http://dx.doi.org/10.1590/S1983-8042201 3000300007

21. Giovanella L, Stegmüller K. Crise financeira europeia e sistemas de saúde: universalidade ameaçada? Tendências das reformas de saúde na Alemanha, Reino Unido e Espanha. Cad Saúde Pública. 2014;30(11):2263-81. DOI: https://doi. org/10.1590/0102-311X00021314

22. Monteiro JK, Dalenogare FS, Santos GO, Rodrigues MLA, Quadros MO, Bratkowski PS, et al. Comunicação $\mathrm{e}(\mathrm{m})$ saúde: relato de experiência com trabalhadores da saúde. Pesq Práticas Psicossoc [Internet]. 2018 [cited 2020 Jan 21];3(2). Available from: http://www.seer.ufsj. edu.br/index.php/revista_ppp/article/view/2969

23. Valduga T.L, Calmon TD, Santos CP. Os sistemas de proteçăo social em Portugal e no Brasil: uma agenda para o Serviço Social. Rev Investig Interv social [Internet]. 2017 [cited 2020 Jan 17];7(12):25-46. Available from: https://revistaseug.ugr.es/index. $\mathrm{php} / \mathrm{tsg} /$ article/view/5188

24. European Observatory on Health Systems and Policies. Portugal. Perfil de saúde do país 2017 [Internet]. Brussels; 2017. Series: State of Health in the EU [cited 2019 May 11]. Available from: https:// ec.europa.eu/health/sites/health/files/state/docs/ chp_pt_portuguese.pdf

Recebido: 24 de março de 2020

Aprovado: 27 de julho de 2020

Publicado: 07 de outubro de 2020

A Revista Baiana de Enfermagem utiliza a Licença Creative Commons - Atribuição-NãoComercial 4.0 Internacional.

https://creativecommons.org/licenses/by-nc/4.0/

Este artigo é de acesso aberto distribuído sob os termos da Licença Creative Commons (CC BY-NC).

Esta licença permite que outros remixem, adaptem e criem a partir do seu trabalho para fins não comerciais. Embora os novos trabalhos tenham de lhe atribuir o devido crédito e não possam ser usados para fins comerciais, os usuários não têm de licenciar esses trabalhos derivados sob os mesmos termos. 